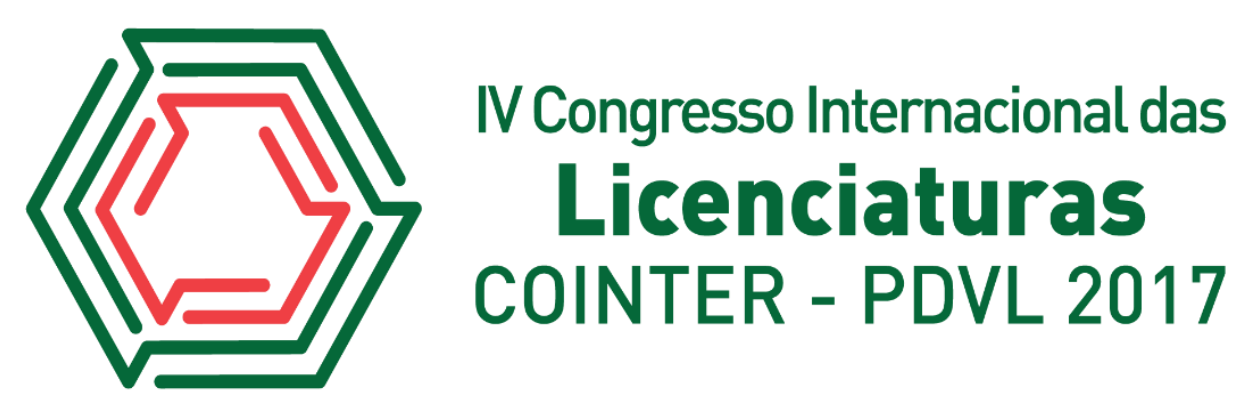

\title{
ANÁLISE DOS IMPACTOS AMBIENTAIS E SOCIAIS NA EXTRAÇÃO DA MICA, QUARTZO E FELDSPATO: UM ESTUDO DE CASO NA LOCALIDADE DO SITIO ÁGUAS BELAS EM PICUÍ- PB
}

\author{
Randson Norman Santos de Souza'; Talita Kelly P.Lucena²; Andreza Agda Dantas Silva ${ }^{3}$; \\ Noely Rayane S. Souza ${ }^{4}$; Bruna Kelly P. Lucena.
}

\section{Introdução}

A extração de minérios é uma das principais fontes de obtenção de insumos essenciais para a vida do homem, apresentando-se como atividade intrinsecamente ligada ao comportamento e aos anseios da humanidade. Isso a torna necessária e indispensável para o equilíbrio do avanço tecnológico, econômico ou social, surge um problema quando foge o controle sobre o ritmo e intensidade de exploração dos recursos naturais (FREITAS, 2011)

Inserido no bioma Caatinga, o município de Picuí, conhecido também como a terra do minério, situa-se na região do Seridó e está localizado geologicamente na Província Pegmatítica da Borborema no Nordeste do Brasil fazendo fronteira com o Estado do Rio Grande do Norte. A região é conhecida por suas riquezas naturais presentes nas rochas pegmatíticas. Os pegmatitos mineralizados são rochas que encontram minerais metálicos, minerais industriais e minerais-gemas (MELO, 2011).

Diante do contexto, o presente artigo tem como objetivo analisar e interpretar a atividade mineradora no município de Picuí, localizado na Microrregião do Seridó Paraibano, remetendo a sua importância econômica, ambiental e social para este setor. Entender tais dinâmicas é de valia para futuros planos de ações.

\section{Fundamentação Teórica}

Promotora de emprego e renda para muitas famílias, a atividade de mineração no Seridó remete ao início do século XX. Reconheceu-se o valor econômico destes minerais a exemplo da tantalita-columbita e berilo, no período da Segunda Guerra Mundial, na oportunidade exportou-se

\footnotetext{
${ }^{1}$ Tecnologia em Agroecologia, IFPB, randsonsantos25@gmail.com

2 Biologia, UFCG, talita_kelly@hotmail.com

${ }^{3}$ Tecnologia em Agroecologia, IFPB, andrezaagda25@gmail.com;

${ }^{4}$ Nutrição, UFCG, noelly rayane@hotmail.com

Mestre em Biotecnologia e Ciências Naturais, UFCG, brunakelly28@hotmail.com.
} 
grandes montantes de minério para fins bélico aos Estados Unidos. Este evento marca o início da trajetória mineral no Seridó (DNPM, 2017).

O município de Picuí apresenta grande ocorrência de pegmatitos ricos em minerais industriais como quartzo, feldspato, albita, caulim e mica, além de minerais metálicos como a tantalitacolumbita (fontes de tântalo e nióbio), e gemas como água marinha e turmalina. Diante deste panorama, podemos considerar que a atividade mineradora em Picuí tem se estruturado a partir da ação conjunta de Estado, Empresas, Cooperativa (COOPICUÍ - Cooperativa dos Mineradores de Picuí) e os próprios garimpeiros que fizeram do meio rural espaço produtivo do setor mineral. Estabeleceu-se assim, uma associação da agricultura com a garimpagem e, essa associação, constitui uma importante estratégia para a manutenção da família.

A atividade também contribui para outros impactos que não podem ser desprezados como, por exemplo, alterações na paisagem, na topografia e nos córregos e açudes, assim como também a elevada quantidade de rejeito exposto e amontoado a céu aberto. Deve-se considerar que a topografia também sofre alterações, pois as galerias e banquetas abandonadas constituem riscos iminentes de acidentes com animais e pessoas despercebidas e desavisadas sobre a existência destas (SILVA, 2011).

A exploração mineral em si, já é uma atividade não sustentável, ou seja, o que foi extraído nunca mais será reposto e existem procedimentos que tem que ser utilizados para minimizar os impactos da atividade como: cobertura vegetal, manutenção da flora e da fauna da região, controle sobre poluição sonora e disposição de dejetos (DNPM, 2009).

\section{Metodologia}

O presente trabalho foi realizado entre os meses de julho e agosto de 2017 em uma mina de extração de minério localizada no sítio de Águas Belas no município de Picui-PB. Porém, apesar de trazer benefícios econômicos aos moradores, essa prática causa alguns impactos no meio ambiente.

O método utilizado foi uma pesquisa descritiva com o intuito de expor características do processo de extração dos seguintes minérios: Quartzo, Mica, Feldspato e Albita. Para tanto, duas visitas foram feitas in loco onde era realizado a extração dos minérios em questão, logo em seguida feita uma entrevista semiestruturada, que foi escolhida com o objetivo de permitir que os entrevistados explanem suas opiniões livremente. As perguntas versavam sobre informações relativas a metodologia do processo de extração, preço, dificuldades enfrentadas, produção mensal e etc. Além disso foram feitos registros fotográficos. 
As visitas foram realizadas periodicamente onde a primeira etapa consistiu da entrevista semiestruturada, com uma conversa livre com o responsável pela mina, o mesmo explanou sobre questões relacionadas à mina. Na segunda etapa foi realizada uma visita a mina onde foi possível visualizar todas as informações citadas na entrevista.

A partir desses dados, podemos montar um panorama geral da extração de alguns minérios no município de Picuí-PB. Do ponto de vista da ética na pesquisa, informa-se, que os trabalhadores foram informados da pesquisa, bem como da sua condição voluntária em participar desta. Desse modo, como forma de resguardar estes profissionais, não será divulgado seus nomes, sendo a sua identidade preservada.

\section{Resultados e Discussões}

O Brasil é o quinto maior país do mundo em extensão territorial e tem a sexta maior produção de mineração do mundo. O setor brasileiro de mineração tem enorme potencial geológico, sendo que a maioria do país ainda não foi explorada (DNPM, 2012).

O Seridó paraibano é um importante produtor de minério. Na Paraíba localizam-se as maiores reservas de argila bentonítica que correspondem aproximadamente $49 \%$ das reservas nacionais. O feldspato que é localizado nas rochas pegmatíticas representa na região do Seridó que detém em termos de reservas o $3^{\circ}$ lugar $(10,4 \%)$ no total do país. Na área de estudo analisada foi observada a extração de Quartzo, Mica, Feldspato e Albita. (Figura 1).

Figura 1: Minérios extraídos (Albita, Quartzo, Mica e Feldspato) no Sítio Águas Belas, município de Picuí-PB.

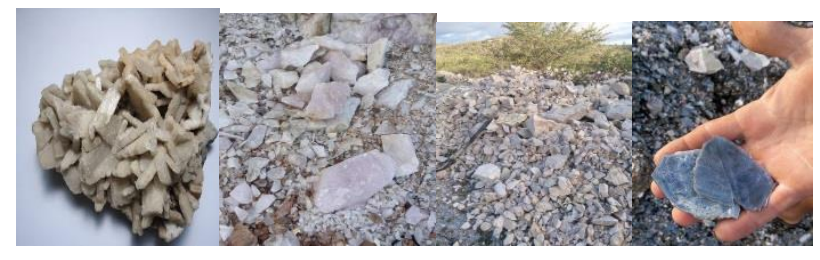

Fonte: Dados da pesquisa, 2017

A exploração é feita com o auxílio de explosivos, compressor e detonador. Tal procedimento torna-se perigoso, pois os trabalhadores não tinham acesso a EPIs (Equipamentos de Proteção Individual), além disso, a área mostrava-se com uma área geográfica acidentada, o que tornava com um maior índice de periculosidade. 
A mina atualmente encontra-se desativada, estando em funcionamento até fevereiro de 2017, tendo como principal justificativa de estar desativado o fato de haver uma grande dificuldade de se obter explosivos, já que a sua compra tem que ser totalmente legalizada, e por ser uma mina de pequeno porte, não possuía os documentos necessários para a compra dos explosivos . A mina contava com três trabalhadores, o que a caracterizava com um local de exploração de pequeno porte. ,

Em relação ao preço (Tabela 1), os mineradores enfrentavam algumas dificuldades em relação ao fato de ter uma produtividade incerta.

Tabela1: Preços atribuídos para a comercialização

\begin{tabular}{c|c}
\hline Minerais & Preço/Tonelada \\
\hline Mica & $35,00 \mathrm{R} \$$ \\
\hline Quartzo & $40,00 \mathrm{R} \$$ \\
\hline Feldspato & $35,00 \mathrm{R} \$$ \\
\hline Albita & $70,00 \mathrm{R} \$$ \\
\hline
\end{tabular}

Fonte: Dados da pesquisa, 2017.

Em relação a produtividade, o responsável pela mina falou que é produzido em torno de 30 toneladas de cada minério. Em relação ao rejeito, este é descartado próximo ao local de extração sem nenhum tipo de tratamento.

\section{Conclusões}

Esta pesquisa é relevante pois mostra a realidade atual de pedreiras de minérios de pequeno porte no município de Picuí -PB. Os dados mostram que há ainda uma carência de informações técnicas por parte desses trabalhadores, e que muitas vezes os mesmos se arriscam em extrações com alto risco e sem a proteção adequada. Em relação aos danos ambientais, foi visto que o processo de extração dos minérios desgasta o solo e contamina os corpos aquáticos, pois para esse processo de extração é necessário fazer escavações e os rejeitos muitas vezes são descartados incorretamente.

Destacam-se também as condições de trabalho precárias e/ou inexistentes dos que trabalham na extração do minério, sem o uso de equipamentos de proteção, comprometendo a saúde dos 
mesmos, concorrendo inclusive riscos de acidentes fatais. Todos os impactos verificados foram caracterizados como negativos e ficou claro que o nível de informação dos garimpeiros influencia diretamente no processamento e resultados finais.

Portanto, é necessário que haja investimento na conscientização técnica desses mineradores para que os mesmos tenham os cuidados necessários com a saúde, segurança e preservação do meio ambiente.

\section{Referências}

DNPM. Departamento Nacional de Produção Mineral. Disponível em: <http://www.dnpm.gov.br/>. Acesso em: 31 jul. 2017.

DNPM, Departamento Nacional de Produção Mineral. Sumário Mineral 2012. DNPM/ MME. Vol. 32, Brasília 2012. Disponível em: www.dnpm.gov.br. Acesso em: Novembro de 2013.

FREITAS, E.; Extração mineral - Os impactos ambientais. 2009. Disponível em: . Acesso em: 23 de agosto de 2011.

MELO, R. O. F. de. A mineração artesanal e de pequena escala em pegmatitos e cerâmica. 2011. 94 f. Dissertação (Mestrado) - Curso de Programa Regional.

SILVA, D. B. Aspectos sócio-econômico-ambiental do processo de extração do caulim no município de Junco do Seridó-PB. 2011. 101 f. Dissertação (Mestrado) - Curso de Programa de Pós-graduação em Geografia do Centro de Ciências Exatas e da Natureza, UFPB, João Pessoa, 2011. 